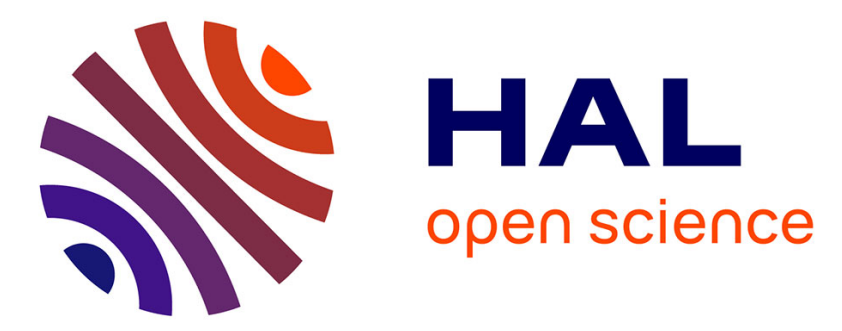

\title{
Experimental and numerical identification of cortical bone permeability
}

Etienne Malachanne, David Dureisseix, Patrick Cañadas, Franck Jourdan

\section{To cite this version:}

Etienne Malachanne, David Dureisseix, Patrick Cañadas, Franck Jourdan. Experimental and numerical identification of cortical bone permeability. Journal of Biomechanics, 2008, 41 (3), pp.721-725. 10.1016/j.jbiomech.2007.09.028 . hal-00325944

\section{HAL Id: hal-00325944 https://hal.science/hal-00325944}

Submitted on 1 Nov 2016

HAL is a multi-disciplinary open access archive for the deposit and dissemination of scientific research documents, whether they are published or not. The documents may come from teaching and research institutions in France or abroad, or from public or private research centers.
L'archive ouverte pluridisciplinaire HAL, est destinée au dépôt et à la diffusion de documents scientifiques de niveau recherche, publiés ou non, émanant des établissements d'enseignement et de recherche français ou étrangers, des laboratoires publics ou privés. 


\title{
Experimental and numerical identification of cortical bone permeability
}

\author{
Étienne Malachanne, David Dureisseix, Patrick Cañadas, \\ Franck Jourdan
}

\begin{abstract}
Laboratoire de Mécanique et Génie Civil, Université Montpellier 2/CNRS UMR 5508, Place Eugène Bataillon, CC 048, F-34095 Montpellier Cedex 5, France
\end{abstract}

\begin{abstract}
Bone is a complex system, and could be modeled as a poroelastic media. The aim of this paper is to identify the macroscopic value of the cortical bone permeability coefficient. A simple experimental method was designed in order to determine the permeability coefficient. Two bone samples taken from different ox femurs were filled with water, to place them under internal pressure. The measurements gave both the fluid flow through the lateral surfaces and the internal pressure. The originality of this work is the coupling between an experimental process and a structural computation performed with a finite element method. The mean cortical bone permeability coefficient identified was about $k=1.1 \times 10^{-13} \mathrm{~m}^{2}$. This value tends to confirm other values found in the literature, obtained by different methods and often at macroscopic scale. It confirms also the domination of vascular permeability (Haversian and Volkmann's canals).

This is a preprint of an article published in its final form as: E. Malachanne, P. Canadas, D. Dureisseix, F. Jourdan, Experimental and numerical identification of cortical bone permeability, Journal of Biomechanics 41(3):721-725, Elsevier, 2008. DOI:10.1016/j.jbiomech.2007.09.028 (c) 2015, Elsevier. Licensed under the Creative Commons Attribution-NonCommercial-NoDerivatives 4.0 International http://creativecommons.org/licenses/by-nc-nd/4.0/
\end{abstract}

Keywords: Permeability; Poroelasticity; Cortical bone; Structural simulation

\section{Introduction}

In order to take into account the complex system of bone microstructure, many authors have relied on poroelasticity theory $[1,2,7,3]$. In this work, we focus on the identification of a poroelastic parameter : the cortical bone permeability. Some values of permeability are given in $[4,8,10,9,5]$, arising from experimental data, analytic developments or numerical simulations. They have been estimated at different scales, leading to a wide dispersion of values. In this communication we propose an identification of permeability at macroscopic level, 
and the objective is to provide a procedure to identify the macroscopic permeability of cortical bones, without using local samples at various locations in the bones, but with a bone slice considered as a struture in its own. Coupling experimental measurements and 3D structural simulations enables identification of the average material characteristics. This procedure is validated on two samples of different ox femurs for which the results are compared with those obtained in the literature.

\section{Specimen preparation, experimental device and results}

The principle of the test bed is to prescribe a water pressure gradient on the sample and to measure the resulting fluid flux throughout the cortical part. Samples were taken from several ox femurs. Ox had been dead for three days when the experimental procedure began and had been preserved at a temperature of $4^{\circ} \mathrm{C}$. Slices of approximately $20 \mathrm{~mm}$ height were cut out, and the marrow was removed. Samples were obtained in the middle of the long axis. This part of femur is less vascularized, which seems to reduce the risk of blood coagulation. Figure 1 shows the first sample after preparation. Because of the structure of a femur, samples were approximately ellipticals with major axis about $70 \mathrm{~mm}$ long for the first sample and $65 \mathrm{~mm}$ long for the second sample and minor axis about $40 \mathrm{~mm}$ long for the first and $43 \mathrm{~mm}$ long for the second. On the lateral surface all the nerves and cartilages were also removed, to obtain a "clean" sample. Finally the cut surfaces are polished in order to ensure a sufficient flatness, and to reduce the roughness.

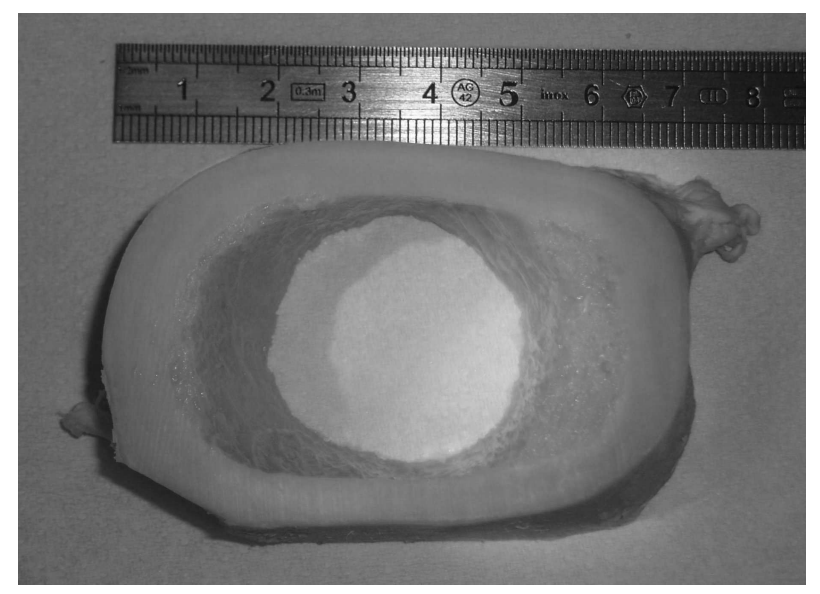

Figure 1: Photography of the first bone sample approximatively elliptical with major axis about $70 \mathrm{~mm}$ long and minor axis about $40 \mathrm{~mm}$ long

The design of the experimental device, see Figure 2, came from permeameters used for permeability measurements of soils. This was simplified to take advantage of the rigidity of the sample. The bone was gripped between two steel plates. Both were bored at their center to connect the internal cavity of 
the sample to a cylindrical capillary tube of $2 \mathrm{~mm}$ calibrated inner diameter $d$, and $3 \mathrm{~m}$ height. The watertightness was ensured by two polymeric joints between the extremal surfaces and the plates. The bottom hole was used for the initial fill-in and to clear the device at the end of the test. Water was injected to fill the sample and the capillary tube, and to pressurize the internal cavity of the sample. After one or two minutes, drops of water appeared on the lateral surface of the bone as shown in Figure 3.

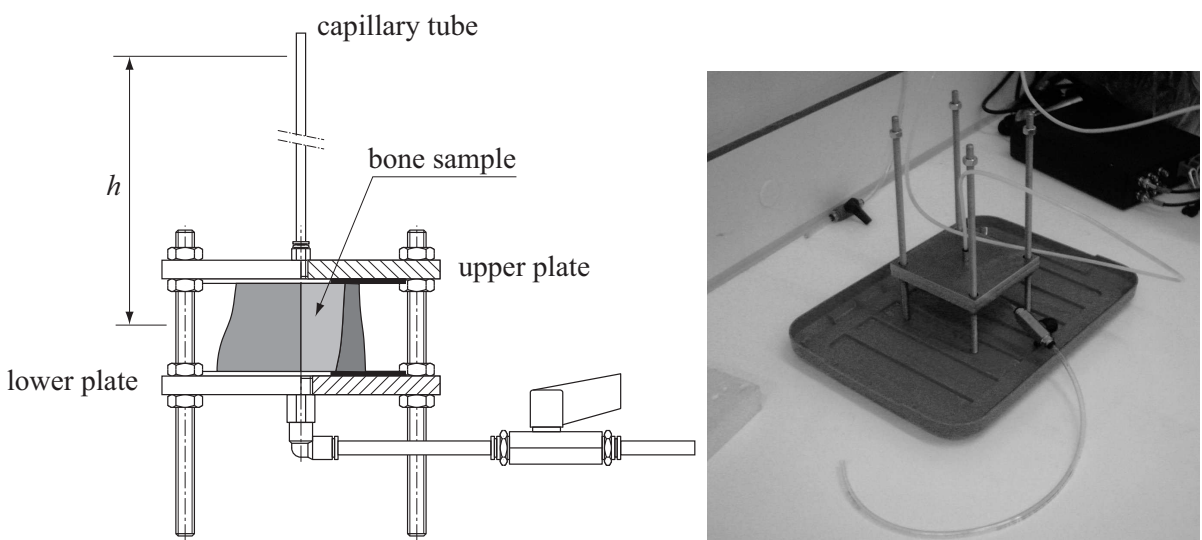

Figure 2: Experimental device. Water is injected at the bottom of a $2 \mathrm{~mm}$ diameter capillary tube

The control of water level in the capillary tube gives both the fluid flow $Q$ through the lateral surface of the sample and the internal pressure $P$. The capillary tube has a sufficiently small section $s=\frac{\pi d^{2}}{4}(d=2 \mathrm{~mm})$ to amplify the measurement of water height variations and to neglect the evaporation effect, though limiting the water celerity $\frac{d h}{d t}$ to assess the validity of hydrostatic Pascal law: $P=\rho g h$ where $g$ is gravity, $\rho$ is the mass density of the fluid. Fluid flow conservation leads to:

$$
Q=-s \frac{d h}{d t}
$$

The model of linear hydraulic resistance states that fluid flow is proportional to pressure difference:

$$
Q=r P
$$

where $r$ is the hydraulic resistance.

Therefore,

$$
\frac{d h}{d t}=-\frac{r}{s} \rho g h
$$

and:

$$
\frac{h}{h_{0}}=e^{-\frac{t}{\tau}}
$$

where $\tau=\frac{s}{r \rho g}$ is a characteristic time scale of the structure (material plus geometry). A test is reported as the evolution of the logarithm of $\frac{h}{h_{0}}$ versus time $t$. We performed five series of tests on five bone samples. The five bone 

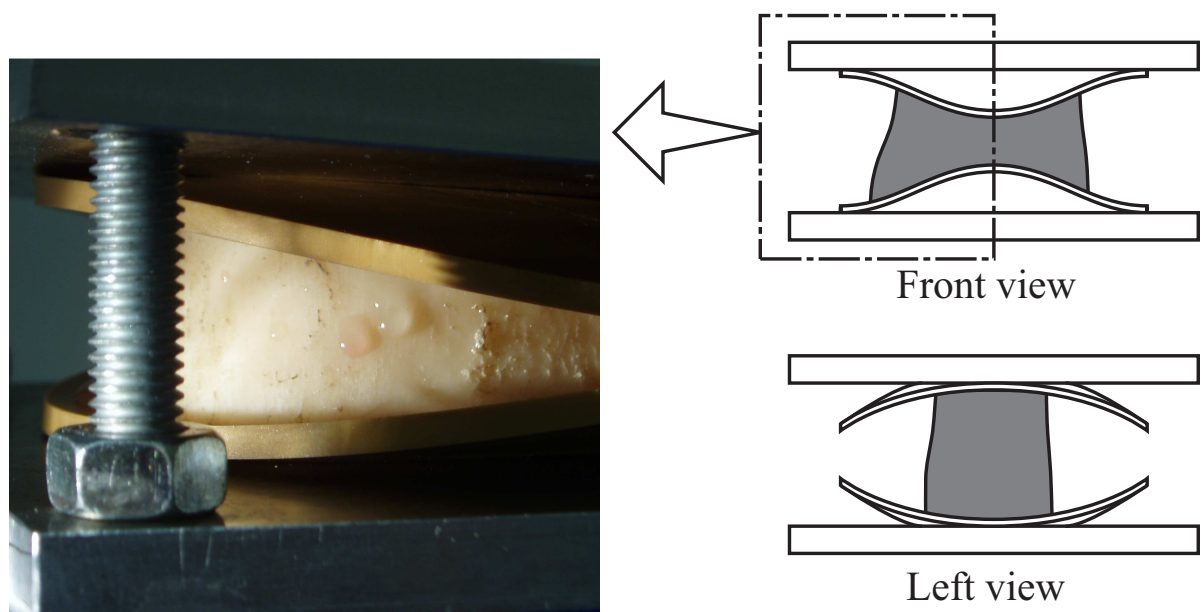

Left view

Figure 3: Bone sample under internal pressure. One may notice on the left picture that drops appear on the lateral surface

samples came from five different oxes. A perfect watertightness was needed because very small flows were measured. A good flatness of extremal surfaces was required because a weak clamping was used to minimise the sample strains. Unfortunately such a watertightness was only ensured for two samples. When the water level on the capillary tube was low, the device was refilled, without changing any conditions. A pause of several minutes was observed between each test. During the first moments of measurement, the liquid passing through the bone was quite colored. Once the water had drained the bone, the outgoing liquid became transparent. We can first observe differences between the five measurements as shown in Figure 4. The linearity of these evolutions validates the hydraulic law (1). Since the slope evolves during the tests differently for each sample, the interpretation of this phenomenon is still unexplained; we chose here to consider only the mean slope $\frac{1}{\tau}$. It is identified as $\frac{1}{\tau}=2.26 \times 10^{-4} \mathrm{~s}^{-1}$ for the first sample and $\frac{1}{\tau}=1.43 \times 10^{-4} \mathrm{~s}^{-1}$ for the second one. Since this is not a material characteristic, the two sets of results on 4 are not directly comparable. A structural computation is required to identify permeability as a material characteristic.

\section{Geometrical and physical model}

To take into account the complex geometry of the samples, CAD numerical models were built, using measured contour sampling points and Bezier-type interpolation within CATIA ${ }^{\mathrm{TM}}$ software, see Figure 5 for the first sample.

Since the tests were quasi-static, we consider that the steady state is always obtained. Darcy's law reads 

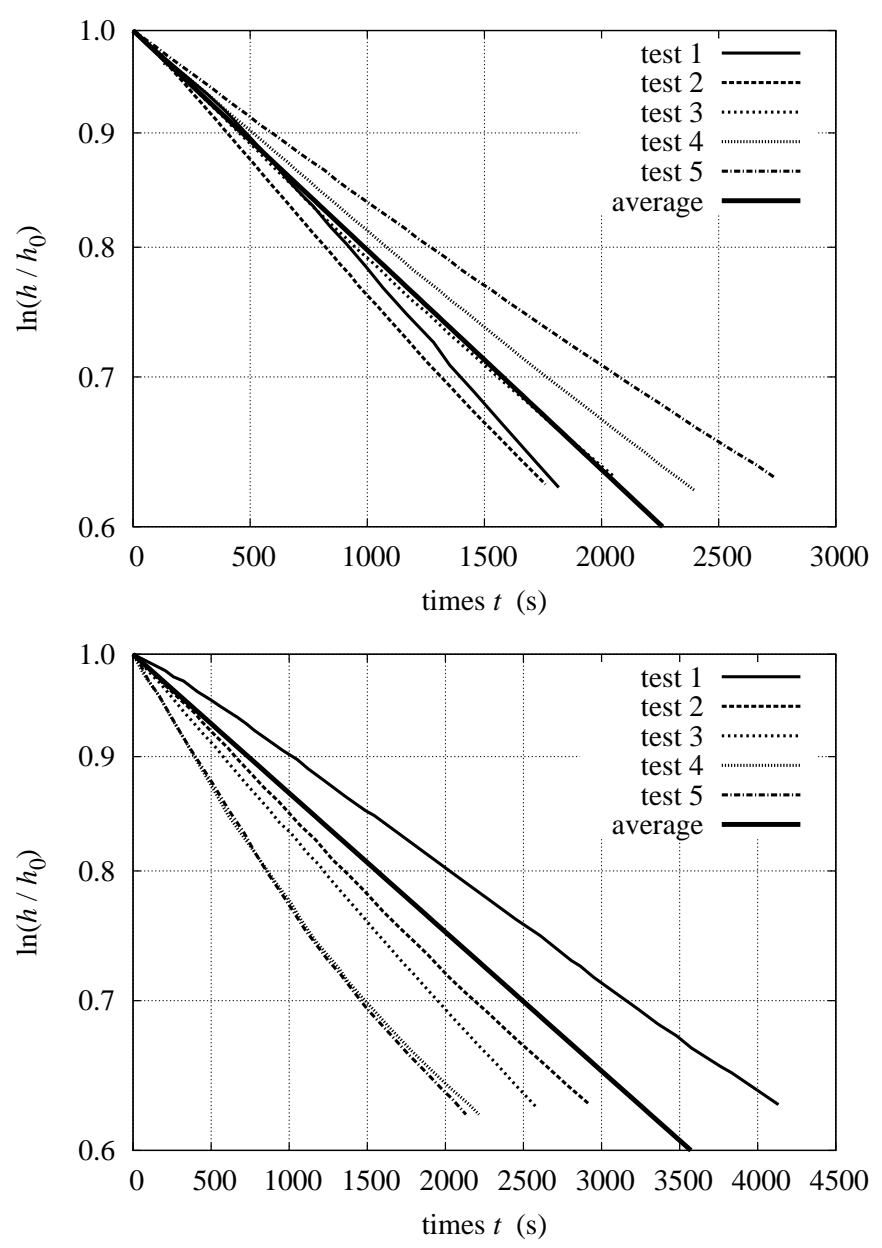

Figure 4: Measurements of water height evolution $h$ normalised by the initial height $h_{0}$ vs. time; for the first sample (top); for the second sample (bottom) 

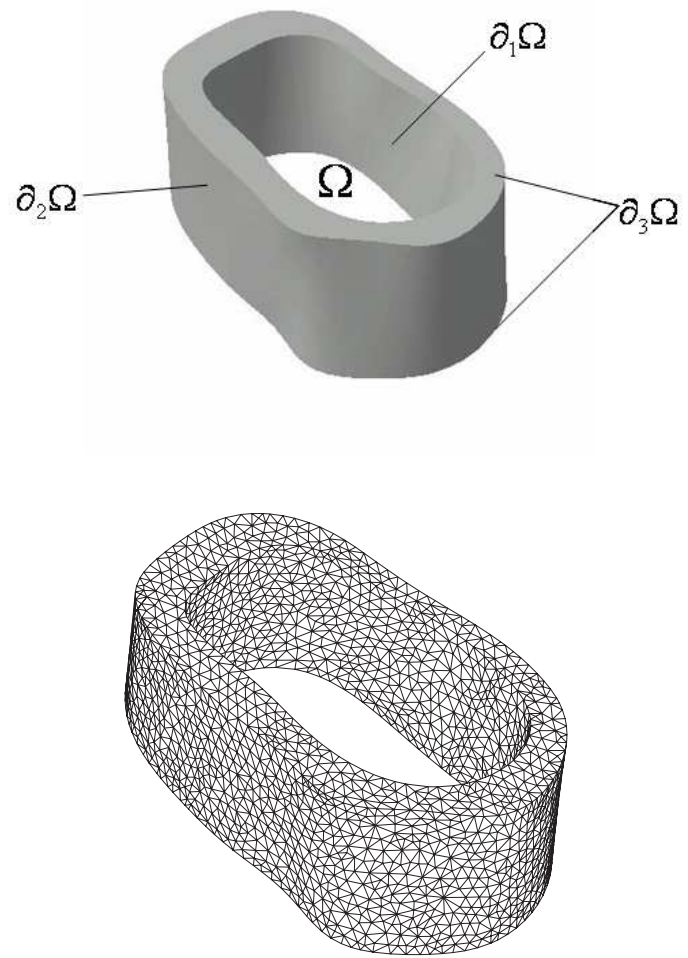

Figure 5: CAD numerical model and mesh of the first bone sample performed with about 30,000 tetrahedral elements. 


$$
\underline{W}=K_{c} \underline{\operatorname{grad}} p \text { on } \Omega
$$

where $\underline{W}$ is the opposite of Darcy velocity and $K_{c}$ is the hydraulic permeability coefficient. The boundary conditions are:

$$
\begin{aligned}
p & =P \text { on } \partial_{1} \Omega \\
p & =0 \text { on } \partial_{2} \Omega \\
\underline{W} \cdot \underline{n} & =0 \text { on } \partial_{3} \Omega
\end{aligned}
$$

$\underline{n}$ being the unitary outwards vector, $\partial_{1} \Omega$ is the internal surface where the inner pressure is applied, $\partial_{2} \Omega$ is the external surface where the outer relative pressure is nil. On the extremal surfaces $\partial_{3} \Omega$, the impervious plates prescribed a nil fluid flow.

Since we used a finite element method, a mesh of the sample was generated with the CAD software (30,000 linear tetrahedral elements were generated). A weak formulation of the problem is to find $p \in \mathcal{P}$ such that:

$$
\forall p^{*} \in \mathcal{P}_{0}, \quad \int_{\Omega} \underline{\operatorname{grad}} p \cdot K_{c} \underline{\operatorname{grad}} p^{*} d \Omega=0
$$

where $\mathcal{P}$ is the set of pore pressure fields $p$ with a finite energy, and $\left.p\right|_{\partial_{1} \Omega}=$ $P,\left.p\right|_{\partial_{2} \Omega}=0 . \mathcal{P}_{0}$ is the associated vector space. After spatial discretization we obtain:

$$
\boldsymbol{H} p=q
$$

$\boldsymbol{H}$ is the permeability matrix, $p$ is the column vector of nodal pressure, $q$ is the column vector of generalised nodal fluid flux. If the degrees of freedom are split into internal ones, with subscript $i$, and degrees of freedom on $\partial_{1} \Omega, \partial_{2} \Omega$ and $\partial_{3} \Omega$ denoted with a subscript $e$ one gets,

$$
\left[\begin{array}{cc}
\boldsymbol{H}_{i i} & \boldsymbol{H}_{i e} \\
\boldsymbol{H}_{e i} & \boldsymbol{H}_{e e}
\end{array}\right]\left[\begin{array}{c}
p_{i} \\
p_{e}
\end{array}\right]=\left[\begin{array}{c}
q_{i} \\
q_{e}
\end{array}\right]
$$

with $q_{i}=0$ and $p_{e}=P u_{e}$ where $u_{e}$ is a boolean vector whose unitary entries correspond to nodes on $\partial_{1} \Omega$. The overall fluid flow is then given by:

$$
Q=u_{e}^{T} q_{e}
$$

Algebraic manipulations lead to the relationship between permeability and total fluid flux is:

$$
Q=u_{e}^{T} \boldsymbol{H}_{e e}^{*} u_{e} P
$$

with the condensed permeability matrix $\boldsymbol{H}_{e e}^{*}=\boldsymbol{H}_{e e}-\boldsymbol{H}_{e i} \boldsymbol{H}_{i i}^{-1} \boldsymbol{H}_{i e} . \quad \boldsymbol{H}$ and $\boldsymbol{H}_{e e}^{*}$ depends lineary on $K_{c}$ and:

$$
\boldsymbol{H}=K_{c} \boldsymbol{H}^{0}
$$

as well as:

$$
\boldsymbol{H}_{e e}^{*}=K_{c} \boldsymbol{H}_{e e}^{*, 0}
$$


The superscript 0 denotes operators obtained with a unitary permeability coefficient. The structural effect is stored in $u_{e}^{T} \boldsymbol{H}_{e e}^{*, 0} u_{e}$ and the material characteristic is given by:

$$
K_{c}=\frac{r}{u_{e}^{T} \boldsymbol{H}_{e e}^{*, 0} u_{e}}
$$

Figure 6 shows the different permeability values identified during the five tests on both samples. The identified permeability coefficient is finally obtained

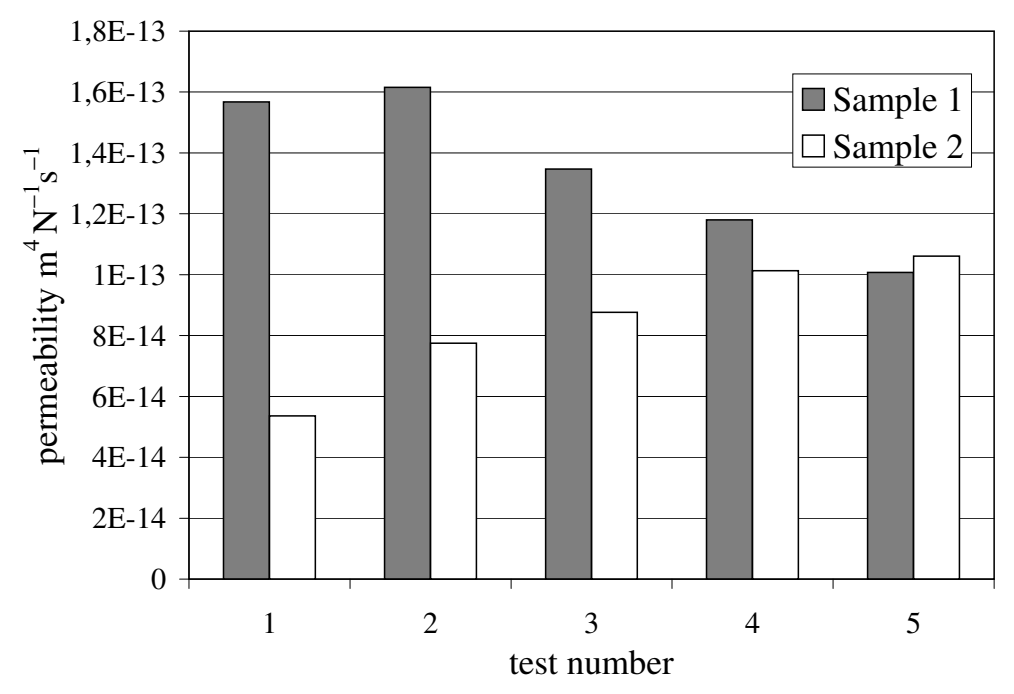

Figure 6: Permeability values identified on first and second sample

as the average of values on Figure6:

$$
K_{c}=1.1 \times 10^{-13} \mathrm{~m}^{4} \mathrm{~N}^{-1} \mathrm{~s}^{-1}
$$

With the water dynamic viscosity $\mu=1$ Pa.s, one gets the intrinsic permeability of the cortical bone $k=\mu K_{c}=1.1 \times 10^{-13} \mathrm{~m}^{2}$. With such a procedure, only radial permeability is found. Other tests with different fluid flow orientations would lead to the full identification of a permeability tensor.

\section{Discussion}

The published studies to determine bone permeability mainly differ in terms of the scale at which experiments were done, and the nature of the bone. For heterogeneous structures, the local permeability is related to a particular location on the bone sample, and several experiments are required to get a representative value. On the other hand, we expect a global permeability measurement to allow the identification of the average value. Zhang et al [10] calculated permeability analytically and obtained $6.36 \times 10^{-13} \mathrm{~m}^{2}$ (at osteon level) and $1.47 \times 10^{-20} \mathrm{~m}^{2}$ (associated to lacunae-canalicular porosity). Smit [9] used a finite element model of an osteon and found $K_{c}=2.2 \times 10^{-19} \mathrm{~m}^{4} \mathrm{~N}^{-1} \mathrm{~s}^{-1}$. So we consider that these permeability values are related to microscopic scales, 
and are below the scale of our study. In [8] an experimental process on cortical bone canine tibiae collected bone plugs at different levels (proximal, middle and distal), and locations of the diaphysis (anterior, medial, lateral and posterior). The mean value of intrinsic permeability was $5 \times 10^{-15} \mathrm{~m}^{2}$.

Our permeability value falls between the value of the vascular permeability given by [10] and the mean permeability found experimentally on dog tibiae in [8]. The discrepancy between these values is probably due to differences in the bone structure (canine tibiae, bone of ox femur and slice location). Finally, bone characteristics are subjected to variability due to the biological process of material creation. Moreover, our value tends to experimentally confirm the theoretical value given by [10] and seems to be close to vascular permeability, higher than lacunae-canalicular permeability. This result agrees with the domination of vascular permeability [10].

Cancellous bone was not removed from our samples but (i) its thickness is smaller than that of the cortical phase, and (ii) its permeability coefficient is considerably higher than the permeability of cortical bone: cancellous bone permeability values in [6] are between $4.65 \times 10^{-10} \mathrm{~m}^{2}$ and $2.33 \times 10^{-10} \mathrm{~m}^{2}$. Consequently, this should not entail the identified value we obtained.

\section{Conclusion}

The aim of this work was to identify a global macroscopic value of cortical bone permeability. In order to take into account the geometry of the sample used and also its mechanical parameters, we associated a structural simulation with an experimental process. Our result agrees with the permeability values obtained by several authors but with a different method and at a different scale, mainly microscopics. Moreover it validates the domination of vascular permeability with respect to flow through porous media. This experimental process gives a measure of global radial permeability of a bone sample through the cortical thickness.

\section{Conflict of interest}

All authors disclose any financial and personal relationships with other people or organisations that could inappropriately influence (bias) their work.

\section{References}

[1] M.A. Biot. Problème de la consolidation des matières argileuses sous une charge. Annales de la Société Scientifique de Bruxelles, B55:110-113, 1935.

[2] M.A. Biot. General theory of three-dimensional consolidation. Journal of Applied Physics, 12:155-164, 1941.

[3] O. Coussy. Mechanics of porous continua. John Wiley \& Sons, 1995.

[4] S.C. Cowin. Bone poroelasticity. Journal of Biomechanics, 32:217-238, 1998. 
[5] M.W. Johnson, D.A. Chakkalakal, R.A. Harper, J.L. Katz, and S.W. Rouhana. Fluid flow in bone in vitro. Journal of Biomechanics, 15:881-885, 1982.

[6] S.S. Kohles, J.B. Roberts, M.L. Upton, C.G. Wilson, L.J. Bonassar, and A.L. Schlichting. Direct perfusion measurements of cancellous bone anisotropic permeability. Journal of Biomechanics, 34:1197-1202, 2001.

[7] R. W. Lewis and B. A. Schrefler. The Finite Element Method in the Static and Dynamic Deformation and Consolidation of Porous Media. John Wiley \& Sons, 2nd edition, 1998.

[8] G. Li, J.T. Bronk, K-N. An, and P.J. Kelly. Permeability of cortical bone of canine tibiae. Microvascular Research, 34:302-310, 1987.

[9] T.H. Smit, J.M. Huyghe, and S.C. Cowin. Estimation of the poroelastic parameters of cortical bone. Journal of Biomechanics, 35:829-835, 2002.

[10] D. Zhang, S. Weinbaum, and S.C. Cowin. Estimates of the peak pressures in bone pore water. Journal of Biomechanical Engineering, 120:697-703, 1998. 